\title{
Editorial: Physical modelling of landslides
}

\section{W. Andy Take}

Professor and Canada Research Chair in Geotechnical Engineering, Queen's University, Kingston, Ontario, Canada

\section{Elisabeth Bowman}

Reader in Geomechanics, Department of Civil and Structural Engineering, University of Sheffield, Sheffield, UK
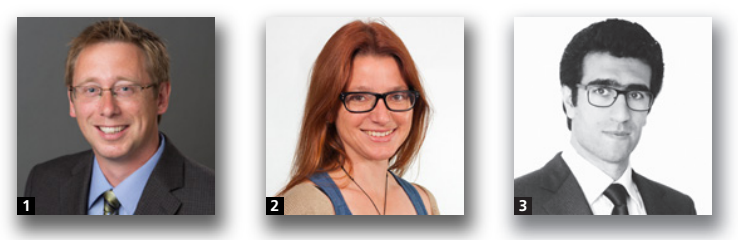

\section{Amin Askarinejad}

Assistant Professor of experimental soil mechanics, Department of Geoscience \& Engineering, Delft University of Technology, Delft, the Netherlands
Landslides, by very nature, exhibit a high degree of unpredictability in their temporal and spatial distribution of occurrence. In contrast, physical modelling provides an opportunity to recreate and study some of the most important aspects of the problem, on demand, and at reduced scale in the laboratory using well-characterised materials. Physical modelling of slope stability problems is not without its challenges. For example, the vertical slopes of a sandcastle are not representative of larger-scale behaviour, as the stability of the castle owes itself to the large relative magnitude of capillarity stresses in comparison to the low self-weight body stresses of the castle. For this reason, the technique of centrifuge modelling, in which centripetal acceleration is used to increase body stresses, is often used to overcome this limitation and permit the exploration of slope stability problems representative of fieldscale behaviour. Indeed, some of the first applications of centrifuge modelling were the collapse of clays slopes under an undrained application of centrifuge acceleration to permit comparison to Taylor's stability charts. As the technique of centrifuge modelling has continued to mature, the ability to introduce fluids to the model has enabled researchers to explore triggering under ever increasingly realistic effective stress paths through the imposition of rising groundwater, rainfall infiltration or evaporative boundary conditions.

The International Journal of Physical Modelling in Geotechnics, in collaboration with Technical Committee TC208 'Slope Stability in Engineering Practice' of the International Society for Soil Mechanics and Geotechnical Engineering, is pleased to present a themed issue entitled 'Physical modelling of landslides' to highlight the latest developments in physical modelling as it relates to the problem of slope stability. The six papers comprising this themed issue continue this tradition of innovation with contributions related to the advanced testing of slope stability processes in both subaerial and submarine landslide applications.

Three manuscripts are included in the themed issue focusing on subaerial landslides. In the first, Lucas et al. (2020) explore the mechanics of triggering of scree slopes; in particular, focusing on the influence of variable depth to bedrock on the groundwater flow required to initiate failure. The work of Kennedy et al. (2020) focuses on the development of physical modelling techniques to explore the complex retrogression behaviour of sensitive clay landslides. Specifically, these authors investigate methods to use cement to create structured materials of bespoke undrained strength and sensitivity to underpin these efforts. Finally, the work of Lei and $\mathrm{Wu}$ (2020) explores the use of piles as landslide-mitigation strategies.

The next three papers of the themed issue focus on submarine landslides. These contributions begin with Tarazona et al. (2020) using physical models to explore how the morphological features of submarine canyons can significantly modify the amplitude, duration and frequency content of free-field seismic ground motions. The work of Hotta et al. (2020) explores the conditions required for the occurrence of hydroplaning and turbidity currents in submarine landslides, while the research of Takahashi et al. (2020) explores the mechanism of earthquake-induced submarine landslides.

This themed issue of the International Journal of Physical Modelling in Geotechnics would not exist without the excellent contributions of the contributing authors, who are thanked for responding to this opportunity. We also gratefully acknowledge the assistance of the editors, Dr Jonathan Knappett and Dr Conleth O'Loughlin, and the many anonymous reviewers 
who volunteered their time to provide helpful and constructive feedback for the authors.

\section{REFERENCES}

Hotta MM, Almeida MSS, Pelissaro DT et al. (2020) Centrifuge tests for evaluation of submarine-mudflow hydroplaning and turbidity currents. International Journal of Physical Modelling in Geotechnics 20(4): 239-253, https://doi.org/10.1680/jphmg.18.00081.

Kennedy R, Siemens G and Take WA (2020) On casting clay specimens of bespoke shear strength and sensitivity for landslide modelling. International Journal of Physical Modelling in Geotechnics 20(4): 198-211, https://doi.org/10.1680/jphmg.18.00082.

Lei G and Wu W (2020) Centrifuge study on the effect of pile bending stiffness on the slope stabilised by piles. International Journal of Physical Modelling in Geotechnics 20(4): 212-223, https://doi.org/10.1680/jphmg.18.00087.

Lucas D, Herzog R, Iten M et al. (2020) Modelling of landslides in a scree slope induced by groundwater and rainfall. International Journal of Physical Modelling in Geotechnics 20(4): 177-197, https://doi.org/10.1680/ jphmg.18.00106.

Takahashi H, Fujii N and Sassa S (2020) Centrifuge model tests of earthquake-induced submarine landslide. International Journal of Physical Modelling in Geotechnics 20(4): 254-266, https://doi.org/10.1680/jphmg.18.00048.

Tarazona SFM, Almeida MCF, Bretschneider A et al. (2020)

Evaluation of seismic site response of submarine clay canyons using centrifuge modelling. International Journal of Physical Modelling in Geotechnics 20(4): 224-238, https://doi.org/ 10.1680/jphmg.18.00084. 